\title{
Avaliação da turbidez em amostras de água tratada coletadas nos municípios do Estado de Goiás
}

\author{
Evaluation of turbidity in treated water samples collected in the municipalities of the State of Goiás
}

Paulo Sergio Scalize ', Neemias Cintra Fernandes 2, Poliana Nascimento Arruda ${ }^{3}$, Nilson Clementino Ferreira ${ }^{4}$, Eduardo Henrique Cunha ${ }^{5}$, Alessandra Francisca dos Santos ${ }^{6}$

\author{
' Doutor, Universidade Federal de Goiás - GO, Brasil. \\ ${ }_{2}^{2}$ Mestre, Instituto Federal de Goiás - GO, Brasil. \\ ${ }^{3}$ Mestranda em Engenharia do Meio Ambiente da Universidade Federal de Goiás - GO, Brasil. \\ ${ }^{4}$ Doutor, Universidade Federal de Goiás - GO, Brasil. \\ ${ }^{5}$ Mestre , Agência Goiana de Regulação, Controle e Fiscalização de Serviços Públicos - GO, Brasil. \\ ${ }^{6}$ especialista, Agência Goiana de Regulação, Controle e Fiscalização de Serviços Públicos - GO, Brasil.
}

\begin{abstract}
Resumo
O presente trabalhou avaliou o parâmetro turbidez em 5.034 amostras coletadas em pontos na rede de distribuição de 224 municípios do Estado de Goiás durante um período de 24 meses, entre 2011 e 2013. Foram coletadas amostras na entrada do sistema, em pontas de rede e em áreas intermediárias com maior fluxo de pessoas, tais como hospitais, postos de saúde, escolas e creches. Os resultados apontaram que no período chuvoso foram constatadas $78,1 \%$ de ocorrências a mais de turbidez com valores acima de 1,0 uT em relação ao período de estiagem, sendo que a média foi de 0,98 e 2,20 uT, respectivamente, para os períodos de estiagem e chuvoso. Foi observada que $23,91 \%$ das amostras analisadas apresentaram valores de turbidez superiores a 1,0 uT e 3,5\% superior a 5,0 uT. Existe uma variação entre os resultados apresentados, sendo de 1,9\% a 8,0\% para as Mesorregiões e de 0 a 8,9\% para as Microrregiões com incidência de turbidez superior a 5,0 uT.
\end{abstract}

Palavras-chaves: turbidez, qualidade da água, portaria 29|4, sazonalidade.

\begin{abstract}
This study evaluated the turbidity of 5034 water samples collected at the water supply systems of 224 municipalities in the State of Goiás during a period of 24 months, between 2011 and 2013. Samples were collected at the beggining, end and also in intermediate points of water supply systems, as well as in areas with increased flow of people, such as hospitals, clinics, schools and nurseries. The results showed that in the rainy season were found $78.1 \%$ of occurrences of turbidity over $1.0 \mathrm{NTU}$ in relation to drought, and the average rate was 0.98 and $2.20 \mathrm{NTU}$, respectively, to periods of drought and rainy. It was observed that $23.91 \%$ of the evaluated samples showed turbidity values greater than $1.0 \mathrm{NTU}$ and $3.5 \%$ greater than $5.0 \mathrm{NTU}$. There is a variation between the results presented, that is from $1.9 \%$ to $8.0 \%$ of the mesoregions and 0 to $8.9 \%$ incidence of microregions with turbidity higher than 5.0 NTU.
\end{abstract}

Keywords: turbidity, water quality, ministerial ordinance 2914, seasonality. 


\section{INTRODUÇÃO}

O controle da qualidade da água distribuída à população é uma necessidade mundial, sendo para isso utilizados parâmetros físicos, químicos, bacteriológicos e radioativos, cujos limites são estabelecidos em legislações, que são criadas e sofrem alterações conforme necessidades e também do conhecimento adquirido em relação ao que pode afetar a saúde da população. Dentre os parâmetros físicos tem-se a turbidez, que é quantificada por uma análise rápida e fornece informações acerca da qualidade da água, permitindo a tomada de decisões nas etapas integrantes de um tratamento de água.

A primeira legislação sobre qualidade da água editada no Brasil foi a Portaria BSB nº 56/1977, que estabeleceu o padrão de potabilidade da água em função dos aspectos microbiológicos e de parâmetros físicos, químicos e organolépticos, não fazendo nenhuma menção quanto ao agente desinfetante. Nela, existia o valor desejável quanto a turbidez de $1,0 \mathrm{uT}$ e o valor máximo permitido de $5,0 \mathrm{uT}$. Treze anos mais tarde foi sancionada a Portaria GM 36/1990, que alterou o valor máximo permitido para turbidez de 1,0 uT na entrada do sistema de distribuição e o valor máximo de 5,0 uT em qualquer ponto da rede desde que demonstrada que a eficácia da desinfecção não fosse comprometia. Trouxe também a recomendação mínima de cloro residual de $0,2 \mathrm{mg} / \mathrm{L}$ em qualquer amostra coletada em pontos da rede de distribuição. Essa Portaria sofreu alterações, evoluindo para a Portaria MS 1469/2000 e, posteriormente, para a Portaria MS 518/2004, semelhantes entre si, ambas contendo a recomendação da manutenção de valores de turbidez na água tratada em 0,5 uT. Mais recentemente a Portaria MS 2914/2011, surgiu com mudanças significativas em termos controle de turbidez, restringindo progressivamente os valores de turbidez admissíveis, de modo que ao final do ano de 2015 , o limite seja 0,5 uT em 95\% das amostras analisadas na saída do sistema de filtração, sendo o limite de 5,0 uT em qualquer ponto da rede de distribuição, mas no máximo em $5 \%$ das amostras.

A Portaria 2914/2011 solicita o monitoramento de cistos de Giardia spp. e oocistos de Cryptosporidium spp. nas situações onde a média geométrica anual de Escherichia coli for igual ou superior a 1.000 NMP/100 mL. Essa necessidade é questionada pela fraca correlação constatada entre esses parâmetros. LOPES et al. (2011) encontraram uma fraca correlação entre turbidez, Escherichia coli e Enterococcus spp. e a presença de oocistos de Cryptosporidium spp. e cistos de Giardia spp. na água da represa de Vargem das Flores na Região Metropolitana de Belo Horizonte. HARRINGTON et al. (2003), XAGORARAKI et al. (2004), também não encontraram uma relação positiva entre essas variáveis, sendo constatado pelos últimos uma maximização da remoção para turbidez abaixo de 0,2 uT.

Existe ainda a consideração de quando a presença de oocistos de Cryptosporidium spp. for maior ou igual a 3,0 oocistos $\mathrm{L}^{-1}$ no ponto de captação de água, é recomendado que o valor seja inferior a 0,3 uT. Para esse item HESPANHOL (2014), relata em seu trabalho que a adoção de turbidez em uma amostra de água como parâmetro para avaliar a presença de oocistos de Cryptosporidium spp. não é tecnicamente suportada, havendo uma correlação pouco significativa. Isso pode ser observado em trabalhos tais como de CERQUEIRA (2008), onde relata que não foram observadas associações entre os padrões de remoção de oocistos em condições de valores de turbidez a 0,5 ou $0,3 \mathrm{uT}$, considerando serem esses limites recomendados por legislações como referência para remoção de oocistos. NASCIMENTO (2009) em sua pesquisa com filtração direta ascendente, relata que não houve correlação significativa entre a concentração de oocistos de Cryptosporidium parvum e os parâmetros turbidez, coliformes totais e E. coli. No entanto, água filtrada com baixa turbidez constitui uma medida preventiva conforme sugerido por LOPES (2009), sendo que em seus resultados não obteve sugestões conclusivas sobre a associação de limites numéricos de turbidez e remoção de oocistos.

Dessa forma, o presente trabalho avaliou a variação de valores de turbidez em 5034 amostras de água tratada coletadas em pontos nos sistemas de distribuição de 224 municípios do Estado de Goiás.

\section{MATERIAIS E MÉTODOS}

Segundo dados do Instituto Brasileiro de Geografia e Estatística (IBGE, 2010) o Estado de Goiás possui 6.004.045 habitantes divididos entre 246 municípios, sendo que destes, 224 municípios tem seus serviços de saneamento operados pela Companhia Estadual, os quais foram objetos do estudo e estão apresentados na Figura 1.

Os municípios foram segregados em 3 grupos considerando suas populações divulgada em 
IBGE, 2010. O Grupo I é formado por municípios com população superior a 250.000 habitantes, onde as coletas foram realizadas trimestralmente. Os três municípios integrantes do Grupo I somam 2.092.659 habitantes, o que representa 34,9\% da população do Estado de Goiás. O grupo II é formado por municípios com população entre 50.000 e 250.000 habitantes, onde as coletas foram realizadas quadrimestralmente. Os treze municípios integrantes desse grupo somam 1.384.299 habitantes, o que representa $23,1 \%$ da população total. O terceiro grupo, Grupo III, é formado por municípios com população inferior a 50.000 habitantes, onde as coletas foram realizadas semestralmente. Esse grupo apresenta 208 municípios, porém com população inferior a soma das populações pertencentes ao Grupo I e II.

A quantidade de amostras foi determinada a partir da necessidade mínima em coletar ao menos uma amostra no início da rede de abastecimento de água e outra amostra em seu final (pontos mais distantes do início da distribuição), de modo a possibilitar uma avaliação do sistema no momento em que a água tratada é disponibilizada para consumo e também em áreas consideradas vulneráveis, tais como as pontas de rede. Outros pontos de coleta foram acrescentados a depender do tamanho do município, tendo sido amostrados pontos onde há maior fluxo de pessoas, tais como hospitais e postos de saúde, escolas e creches, conforme estabelecido pela Portaria 2.914 (BRASIL, 2011). A frequência e quantidade de amostras coletadas estão indicadas na Figura 1 e totalizam 5034 amostras. O período de estudo se deu entre 2011 e 2013 , totalizando 24 meses.

As coletas e preservação das amostras foram executadas conforme Guia Nacional de Coleta e Preservação de Amostras (CETESB, 2011). As amostras foram submetidas a análise de turbidez empregando o métodos 2130B, conforme preconizado no Standard Methods (APHA, 2005).

Visando a verificação da interferência sazonal na qualidade de água quanto a turbidez, os resultados foram analisados considerando dois períodos, chuvoso (janeiro a março e outubro a dezembro) e de estiagem (abril a setembro).

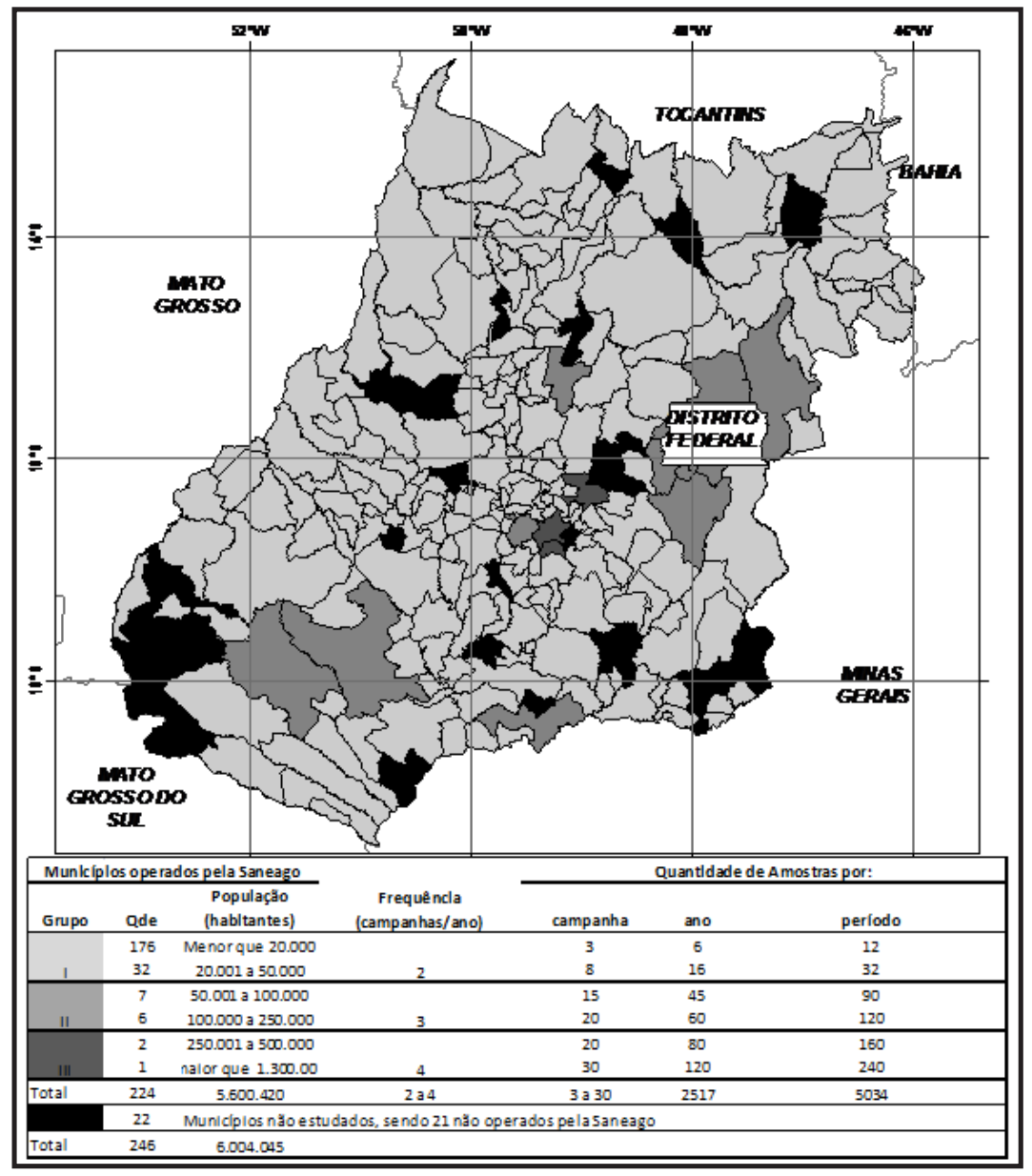

Figura 1. Estado de Goiás com a distribuição dos municípios em função da população, indicando o número de amostras coletadas em cada uma deles. 
Para possibilitar a espacialização racional dos resultados obtidos nessa pesquisa, os municípios do Estado de Goiás foram separados conforme classificação do IBGE regulamentada pela Resolução da Presidência da República (PR) nº 11, de 05 de junho de 1990. A resolução divide os 246 municípios goianos em 5 mesorregiões geográficas, e destas divididas em 18 microrregiões geográficas, que são: Anicuns, Anápolis, Aragarças, Catalão, Ceres, Chapada dos Veadeiros, Entorno do Distrito Federal, Goiânia, Iporá, Meia Ponte, Pires do Rio, Porangatu, Quirinópolis, Rio Vermelho, Sudoeste, São Miguel do Araguaia, Vale do Rio dos Bois e Vão do Paraná. A espacialização das mesorregiões do Estado de Goiás encontra-se ilustrada na Figura 2.

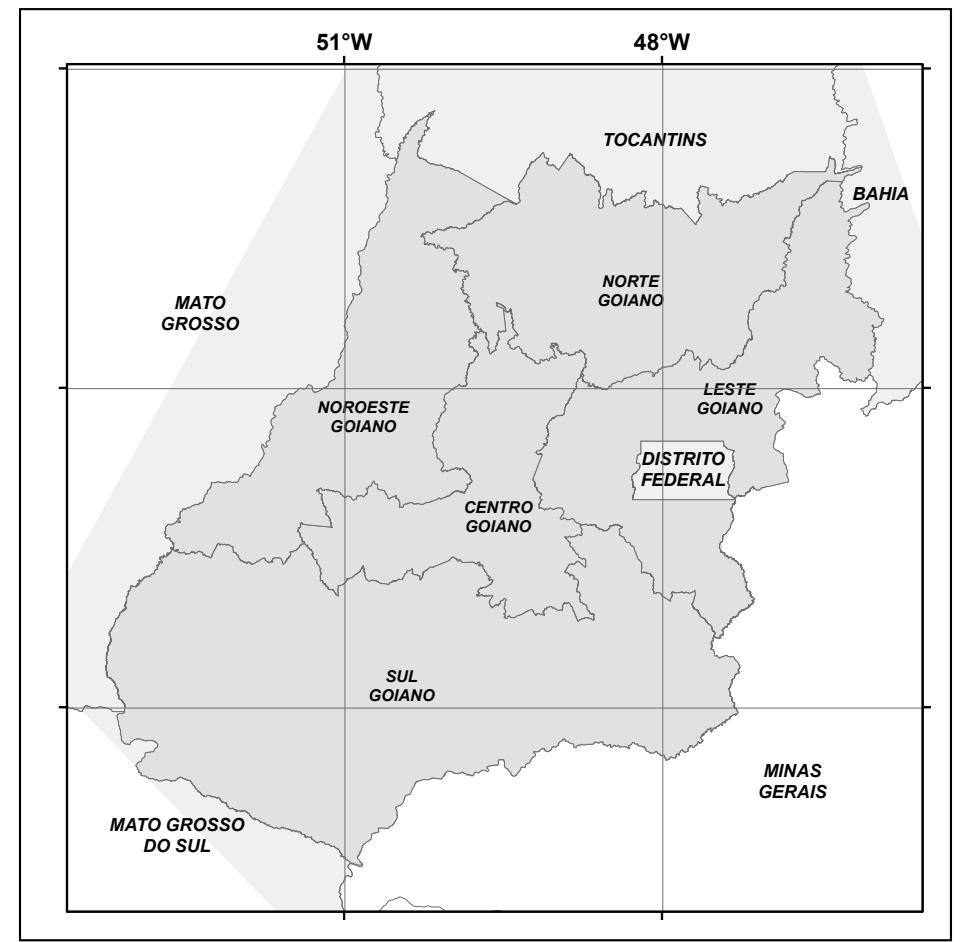

Figura 2 - Composição das mesorregiões geográficas do estado de Goiás.

\section{RESULTADOS E DISCUSSÃO}

Avaliando os resultados de turbidez em todas as amostras coletadas no período de estudo, temos que $76,9 \%$ se apresentam com valores abaixo de $1,0 \mathrm{uT}, 20,41 \%$ entre 1,01 e 5,0 uT e $3,5 \%$ acima de $5,0 \mathrm{uT}$ (Tabela 1).

Quando os resultados foram avaliados separadamente entre os períodos de estiagem e chuvoso, foi observado que na estiagem, os valores de turbidez são inferiores aos encontrados no período chuvoso, sendo que o valor médio passa de $0,98 \mathrm{uT}$ para $2,20 \mathrm{uT}$, respectivamente. Na Tabela 1 pode ser observada que, no período chuvoso, a ocorrência de turbidez acima de 1,0 uT, foi 78,1\% superior a registrada no período de estiagem. Nesse mesmo período foi constatada que $82,23 \%$ das amostras analisadas estão com turbidez inferior a $1,0 \mathrm{uT}$, contra $63,35 \%$ no período chuvoso (redução de $16,9 \%$ ).

Na Figura 3 pode ser observada as variações dos valores de turbidez distribuídas por faixas de medições, ou seja, foram avaliadas todos os resultados de cada faixa. Nota-se que os valores da mediana foram de 0,$2 ; 0,7 ; 1,6$ e 9,7 uT, respectivamente para as 4 faixas de medições. Os valores atípicos para as duas últimas faixas não foram inseridas no gráfico, devido a grande variação, o que prejudicaria a observação no gráfico.

$\mathrm{Na}$ Figura 4 é apresentada a distribuição de incidência de turbidez pelas 5 Messorregiões. Pode ser observada a maior quantidade de amostras com ocorrência na faixa igual ou inferior a 0,5 uT, variando de 45,9 a 58,3\%. Com relação a valores superiores a 5,0 uT foi encontrada uma variação entre 1,9 e $8,0 \%$. 
Na Figura 5 pode ser observada a incidência de valores de turbidez apresentadas entre suas faixas de variação nas Microrregiões. A ocorrência de turbidez acima de 5,0 uT ocorre em menos de $5 \%$ das amostras estratificadas por microrregiões, com exceção de dois valores atípicos de 8,7 e 8,9\%. A maioria dos valores encontrados para turbidez estão na faixa menor ou igual a $0,5 \mathrm{uT}$, variando de 44,7 a $63,4 \%$.

Avaliando as amostras segregadas por Mesorregião e Microrregião em todo o período de estudo, a incidência de ocorrência de turbidez superior a 1,0 uT variou de $12,7 \%$ a $37,5 \%$ nas microrregiões e de 19,78\% a 32,94\% quando consideras as Mesorregiões. Com exceção da Microrregião de Aragarças, as demais apresentaram valores maiores que 5,0 uT em pelo menos uma amostra analisada.

Segundo Portaria 2.914/2011, o limite máximo permitido para o valor de turbidez em amostras coletadas em qualquer ponto da rede distribuição é de 5,0 uT, dessa forma, existe locais em desacordo com a legislação vigente.

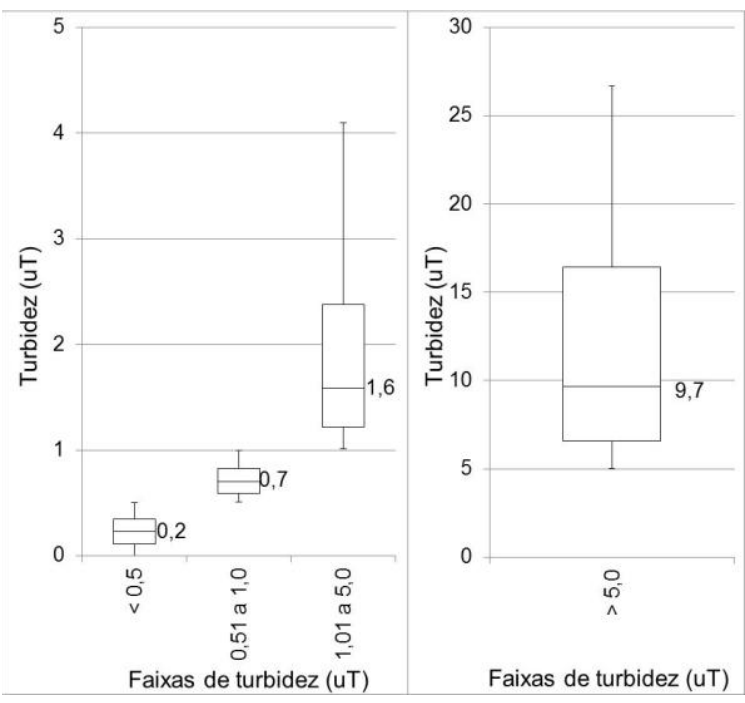

Figura 3 - Variações dos valores de turbidez distribuídas por faixa de leitura, com destaque para os valores da mediana.

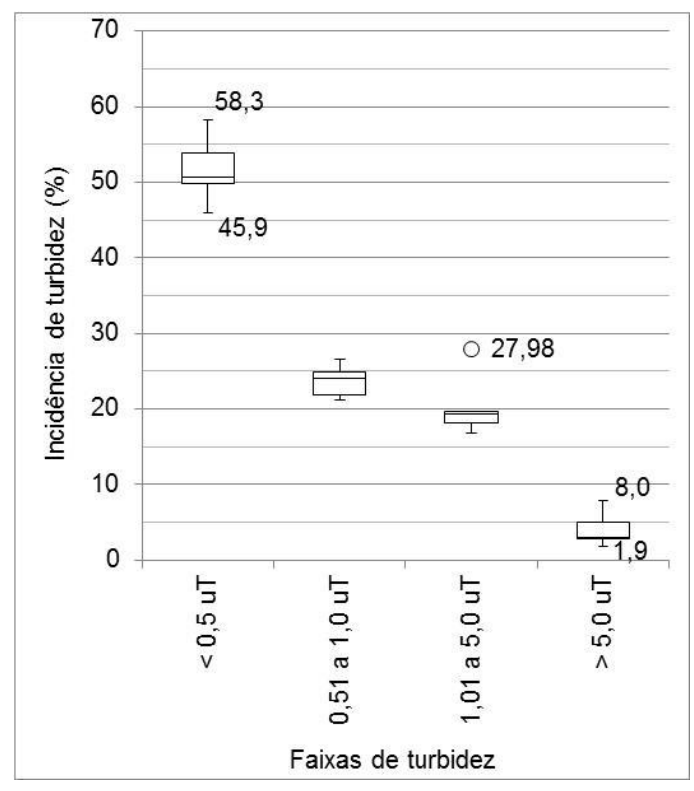

Figura 4 - Incidência de turbidez em função de suas faixas apresentadas nas Mesorregiões.

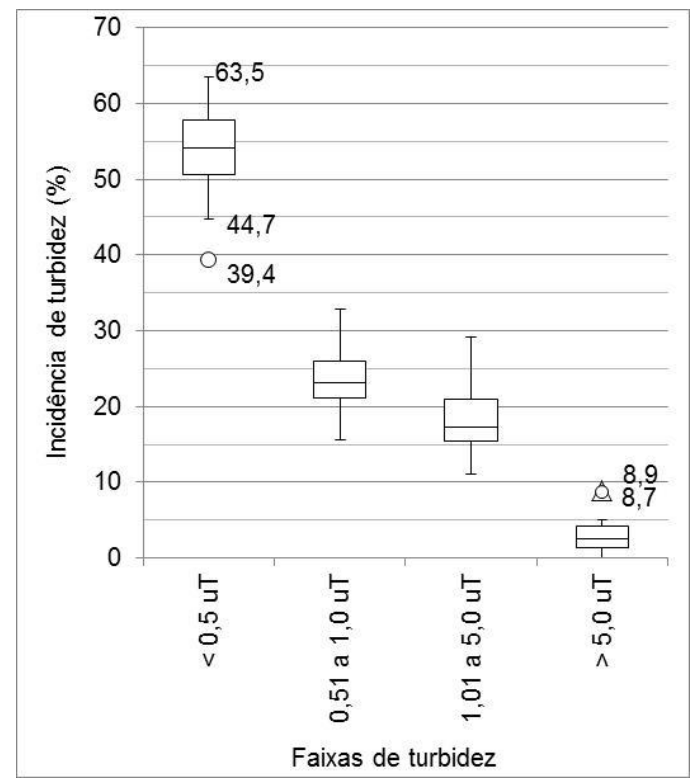

Figura 5 - Incidência de turbidez em função de suas faixas apresentadas nas Microrregiões. 
Tabela 1 - Quantidade de resultados em cada faixa de turbidez nas amostras de água coletadas nas microrregiões do estado de Goiás.

\begin{tabular}{|c|c|c|c|c|c|}
\hline \multirow{2}{*}{ Mesorregião } & \multirow{2}{*}{ Microrregião } & \multicolumn{4}{|c|}{ Ocorrências nas faixas de turbidez (\%) } \\
\hline & & $\leq 0,5 \mathrm{uT}$ & 0,51 a 1,0 uT & 1,01 a 5,0 uT & $>5 \mathrm{uT}$ \\
\hline \multirow{6}{*}{ Centro Goiano } & Anápolis & 51,8 & 24,6 & 20,8 & 2,9 \\
\hline & Anicuns & 61,2 & 21,4 & 15,8 & 1,5 \\
\hline & Ceres & 71,8 & 15,6 & 11,0 & 1,7 \\
\hline & Goiânia & 55,6 & 22,7 & 17,5 & 4,2 \\
\hline & Iporá & 55,5 & 26,6 & 17,2 & 0,8 \\
\hline & Geral Mesorregião & 58,27 & 21,94 & 16,87 & 2,91 \\
\hline \multirow{3}{*}{ Leste Goiano } & Entorno do Distrito Federal & 44,7 & 21,2 & 29,1 & 5,0 \\
\hline & Vão do Paranã & 53,9 & 21,1 & 20,4 & 4,6 \\
\hline & Geral Mesorregião & 45,88 & 21,18 & 27,98 & 4,96 \\
\hline \multirow{4}{*}{ Noroeste Goiano } & Aragarças & 52,6 & 32,8 & 14,7 & 0,0 \\
\hline & Rio Vermelho & 59,6 & 23,1 & 16,3 & 1,0 \\
\hline & São Miguel do Araguaia & 39,4 & 23,1 & 28,8 & 8,7 \\
\hline & Geral Mesorregião & 50,62 & 26,54 & 19,75 & 3,09 \\
\hline \multirow{3}{*}{ Norte Goiano } & Chapada dos Veadeiros & 54,2 & 26,4 & 15,3 & 4,2 \\
\hline & Porangatu & 48,8 & 23,5 & 18,8 & 8,9 \\
\hline & Geral Mesorregião & 49,86 & 24,11 & 18,08 & 7,95 \\
\hline \multirow{7}{*}{ Sul Goiano } & Catalão & 57,9 & 16,4 & 24,3 & 1,4 \\
\hline & Meia Ponte & 53,6 & 28,5 & 14,8 & 3,0 \\
\hline & Pires do Rio & 50,0 & 18,0 & 29,7 & 2,3 \\
\hline & Quirinópolis & 63,5 & 18,3 & 16,3 & 1,9 \\
\hline & Sudoeste de Goiás & 50,2 & 28,5 & 21,1 & 0,2 \\
\hline & Vale do Rio dos Bois & 57,3 & 25,0 & 14,0 & 3,7 \\
\hline & Geral Mesorregião & 53,85 & 24,88 & 19,41 & 1,85 \\
\hline \multirow{2}{*}{\multicolumn{2}{|c|}{ Todas amostras }} & 53,10 & 22,99 & 20,41 & 3,50 \\
\hline & & \multicolumn{2}{|c|}{76,09} & \multicolumn{2}{|c|}{23,91} \\
\hline \multirow{2}{*}{\multicolumn{2}{|c|}{ Período Chuvoso }} & 48,34 & 20,01 & 26,26 & 5,40 \\
\hline & & & 68,35 & \multicolumn{2}{|c|}{31,65} \\
\hline \multirow{2}{*}{\multicolumn{2}{|c|}{ Período de Estiagem }} & 56,87 & 25,36 & 15,78 & 1,99 \\
\hline & & & 82,23 & \multicolumn{2}{|c|}{17,77} \\
\hline
\end{tabular}

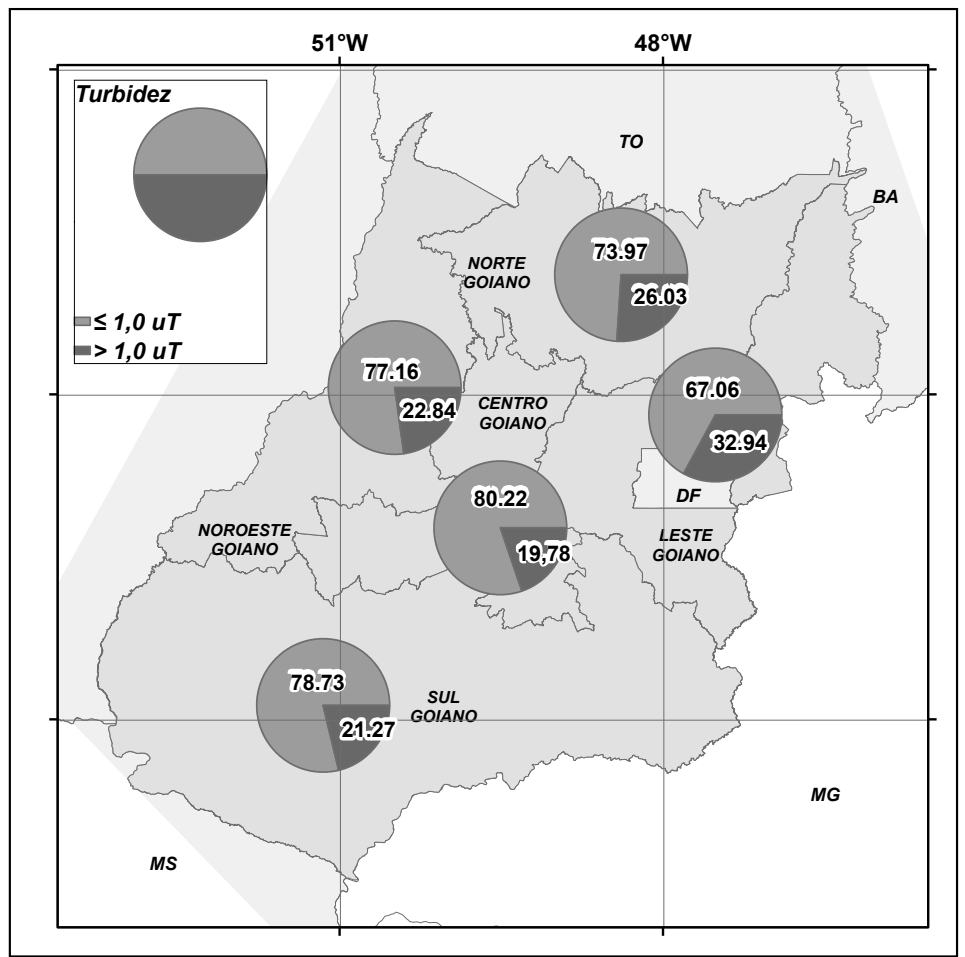

Figura 6 - Incidência de turbidez nas Mesorregiões do Estado de Goiás. 
Na Figura 6 podem ser observadas as incidências de turbidez igual ou abaixo de 1,0 uT e acima de 5,0 uT para as Mesorregiões do Estado de Goiás. Nota-se que o Centro Goiano apresenta uma melhor situação com $80,22 \%$ de amostras com turbidez menor ou igual a 1,0 uT, seguidas do Sul e Noroeste Goiano com 78,73\% e 77,16\%, respectivamente. As Mesorregiões Norte e Leste Goiano apresentaram a pior situação sendo de $73,97 \%$ e $67,06 \%$.

\section{CONCLUSÕES}

O presente trabalho permitiu concluir que $23,91 \%$ e $3,5 \%$ das amostras analisadas apresentam turbidez superior a 1,0 uT e 5,0 uT respectivamente. A qualidade da água distribuída à população de estudo é influenciada, em termos de turbidez, pelo período chuvoso, apresentando 78,1\% de ocorrências de turbidez acima de 1,0 uT, em relação ao período de estiagem. Com relação a valores abaixo de $1,0 \mathrm{uT}$, foi constatada uma queda de $16,9 \%$ no período chuvoso. Isso indica que a qualidade da água tratada foi influenciada pelos períodos sazonais para o parâmetro estudado.

Foi constatada que existe variação dos valores de turbidez entre as Meso e Microrregiões, variando, respectivamente, de 1,9 a $8,0 \%$ e 0 a $8,9 \%$ de incidência de turbidez superior a 5,0 uT.

\section{AGRADECIMENTOS}

Os autores agradecem pelo projeto firmado entre a Agência Goiana de Regulação (AGR) e a Fundação de Apoio a Pesquisa (FUNAPE), Universidade Federal de Goiás (UFG) com interveniência da Escola de Engenharia Civil (EEC).

\section{REFERÊNCIAS}

APHA. STANDARD METHODS FOR THE EXAMINATION OF WATER AND WASTEWATER, 21 ed., 2005.

BRASIL. Ministério da Saúde. Portaria no 56, de 14 de Março de 1977. Brasília, 1977.

Ministério da Saúde. Portaria no 36, de 19 de janeiro de 1990. Brasília, 1990.

Presidência da República. Resolução nº 11 de 5 de junho de 1990. Divide o estado de Goiás em 18 microrregiões geográficas. Brasília, 1990.

Ministério da Saúde. Portaria no 1469, de 29 de dezembro de 2000. Brasília, 2000.

Ministério da Saúde. Portaria MS nº 518, de 25 de março de 2004. Brasília, 2004.

Ministério da Saúde. Portaria MS n 2914, de 12 de dezembro de 2011. Brasília, 2011.

CERQUEIRA , D.A. Remoção de oocistos de Cryptosporidium parvum e de indicadores no tratamento de água por ciclo completo, filtração direta descendente e dupla filtração, em escala piloto. Originalmente apresentada como tese de doutorado, Departamento de Engenharia Sanitária e Ambiental, Departamento de Engenharia Hidráulica e Recursos Hídricos, Universidade Federal de Minas Gerais, 2008.

CETESB. Guia nacional de coleta e preservação de amostras. São Paulo: CETESB, 325p., 2011.

HARRINGTON, G.W., XAGORARAAKI, I., SSAVASILASUKUL, P., STANDRIDGE, J.H. Effect of filtration conditions on removal of emerging waterborne pathogens. Journal of the American water works association, v. 95 (12), p.95-104, 2003. 
HESPANHOL, I. Normas Anormais. Revista Dae. nº 194 jan/abr, p.6-23, 2014.

IBGE. Censo Demográfico 2010. Instituto Brasileiro de Geografia e Estatística, 2011.

SNIS - Sistema Nacional de Informações sobre Saneamento: Diagnóstico dos serviços de água e esgotos 2011. Brasília, 2013.

LOPES, A.M.M.B. et al. Ocorrência de oocistos de Cryptosporidium spp. e cistos de Giardia sp e sua associação com Escherichia coli, Enterococcus spp. indicadores bacteriológicos e turbidez em um reservatório tropical. Revista Dae, no , p. 18-28, 2011.

LOPES, G.J.R. Avaliação da turbidez e do tamanho de partículas como parâmetros indicadores da remoção de oocistos de Cryptosporidium spp. nas etapas de clarificação no tratamento da água em ciclo completo. Originalmente apresentada como Tese de Doutorado. Universidade Federal de Viçosa, 2008.

NASCIMENTO, M.F. Remoção de oocistos de Cryptosporidium por meio da filtração direta ascendente em areia: avaliação em escala piloto. Originalmente apresentada como dissertação de mestrado - Universidade de Brasília. Faculdade de Tecnologia, 2009.

XAGORARAKI, I., HARRINGTON, G. W., ASSAVASILAVASUKUL, P., STANDRIDGE, J. Removal of emerging waterborne pathogen. Journal Awwa, v. 93:2 (May), p.102-113, 2004. 